\title{
Separated Magnet Yoke for Permanent Magnet Linear Generator for Marine
}

\section{Wave Energy Converters}

\author{
N. P. Gargov, A. F Zobaa, I. Pisica
}

\begin{abstract}
In this paper the performance of a longitudinal flux Permanent Magnet Linear Generator (PMLG) for Wave Energy Converters (WEC) is investigated. The influence of the number of slots per pole, phase $q$ and the number of stator's winding sections are analysed. The power output and the cogging forces in the PMLG are calculated and reviewed with respect to the above design parameters. In addition, an optimized PMLG model is designed and simulated. Three-dimensional Finite Element Method (FEM) is used for solving the combined field and circuit equations of the generator.
\end{abstract}

Index Terms - cogging forces, finite element method, permanent magnet linear generator, wave energy converter

\section{INTRODUCTION}

DUE to the nature of marine waves, the take-off device for WECs usually operates between 0 and $2 \mathrm{~m} / \mathrm{s}$. Currently, some of the deployed WECs are designed to work with fast-speed rotational generators. In such systems, the relatively low-speed linear translation of the take-off device has to be converted to a high-speed rotational motion via an interface system. By integrating such system, the overall complexity of the WEC is increasing, whereas the efficiency and the robustness are reduced. A possible solution for overcoming such problems is 
a wave energy converter with a direct drive linear generator [1-4]. The linear generators are proposed for WECs to simplify the overall structure. The main problems with the linear generators are the high magnetic forces appearing between stator and translator during normal operation. These forces could reduce the lifetime of the bearings and therefore, increase the maintenance costs of the WEC. Hence, reduction of the magnetic forces in the linear generator may have significant effect on the maintenance cost.

Direct drive PMLGs have been proposed for WECs and several design solutions have been outlined in [4-12]. In [4] flat air-cored design has been suggested. The design has the advantage of eliminating the cogging force due to absence of stainless steel in the stator however, in order to generate sufficient magnetic field in the large air gap, an extra Permanent Magnets (PMs) are needed which on the other hand could increase the price of the machine.

A switched reluctance PMLG has been presented in [9]. The machine has iron-cored magnetic yokes and therefore, low magnetic reluctance path is provided however, high level of latching (cogging) forces can be expected due to the alignment of the stator and the translator. Another PMLG with excitation provided by a super conducting DC coil has been proposed in [13]. This kind of generator generally advantages from the possibility of control excitation applied on the excitation winding. On the other hand, heavy saturation in the magnetic core has been reported.

Furthermore, observations on the cogging forces $[14,15]$ and the generated voltage harmonics [16] have also been performed on similar structure as structure presented in this paper. Additionally, constant speeds or speeds having sinusoidal shapes are common approximations for simulating PMLGs [14, 16-19].

In this paper, a design for a flat longitudinal PMLG for marine wave energy is analysed. The influence of parameters, such as: the number of slots per pole, phase $q$, and the number of stator's winding sections are analysed with respect to the cogging forces and the output power of the PMLG. Based on the obtain results, an optimal model is proposed. The aims of the optimization are reduction of the magnetic attraction forces between stator and translator and also increase of the electrical power output of the PMLG. By reducing the magnetic attraction force, the maintenance cost of the WEC can be reduced. Likewise, increasing the power output of the generator will reduce the pay-back time of the WEC. 
FEM is used as a simulation tool because of its high accuracy. Moreover, the simulations are performed using three-dimensional FEM with a time-varying electromagnetic field taking into consideration the non-linearity of the magnetic cores and the longitudinal ends of the machine. Furthermore, in the simulations full size generator models taking into account the magnetic flux distribution in the air gap and the regions at the longitudinal ends are simulated. Additionally, in order to simulate real sea conditions, an experimentally recorded vertical wave displacement is applied to the generator's translator for a period of 20 seconds.

The paper is organized as follows: after the introduction, a description of WEC is outlined. Then a theoretical explanation of the nodal force method used in the FEM is given. After that, a description of the investigated PMLG is given. In the next section, the results from the investigation are displayed and an optimal model is designed, before conclusions are presented.

\section{WAVE ENERGY CONVERTER AND FORCES CALCULATIONS}

Wave Energy Converter is a general title for devices that convert the kinetic energy of marine waves to electricity. The investigated PMLG in this paper is designed to be driven by a floater on the water surface, or installed in an Archimedes wave swing [20].

Generally, two types of construction employing either a non-flexible shaft [21] or a rope [22, 23] have been proposed for WECs having direct drive electrical generators. The design using a non-flexible shaft is simpler, but it has only one degree of freedom and the energy absorption is limited up to $50 \%$ [24]. Furthermore, the forces normal to the motion axis are likely to be higher when using the non-flexible shaft design due to the restriction of the motion of the translator.

Conversely, an advantage of the design using a rope is that the flexibility of the rope provides additional degrees of freedom and hence, the energy absorption can be increased. Another difference in design is given by the springs, which have to be installed in order to pull the translator back to its lowest point.

Owing to the direct coupling of the take-off device and the generator, the generated voltage and the electrical frequency are in direct ratio with the translator's speed [25]. As a result, big fluctuations in the output voltage and the electrical frequency are observed during normal 
operation of the PMLG. In order to stabilize the fluctuation, a power-electronics converter and energy storage can be installed between the generator and the grid [26].

The calculation of the cogging forces is interesting from many perspectives. It is an important parameter for studying: the generator bearing system, the mechanical stress, and fatigue in the supporting structure. Additionally, the cogging forces are source of sound emission.

In this paper, the forces are calculated by FEA using 3D models with high mesh resolution. To increase the result accuracy the resolutions of the models have been set to around 1 million mesh nodes. The FEA software uses the nodal force method [27] as a tool for magnetic forces calculation. The nodal force method is derived from the Maxwell stress tensor and the method is proven to be as accurate as the virtual work method $[27,28]$.The surface forces and the magnetic volume can be derived from the Maxwell stress tensor as follows:

$$
\begin{gathered}
f_{i}^{\Omega}=\partial_{k} T_{i k} \\
f_{i}^{\Gamma}=\left(\left.T_{i k}\right|_{2}-\left.T_{i k}\right|_{1}\right) n_{k}
\end{gathered}
$$

- $n_{k}$ is the outward unit normal vector in region one and Maxwell stress tensor

- $T_{i k}$ is given as:

$$
T_{i k}=H_{i} B_{k}-\delta_{i k} w_{m}
$$

$-\delta_{\mathrm{ik}}=\left\{\begin{array}{ll}1 & i=k \\ 0 & i \neq k\end{array}\right.$ is the Kronecker`s delta

- $w_{m}$ is the magnetic co-energy density of the element:

$$
w_{m}=\int_{0}^{H} B \cdot d H .
$$

For virtual displacement $\delta l_{i}$ the virtual work done by magnetic volume and surface force is:

$$
\delta W=\int f_{i}^{\Omega} \delta l_{i} d v+\int f_{i}^{\Gamma} \delta l_{i} d \Gamma
$$




$$
\begin{gathered}
=\int\left(\partial_{i} T_{i k}\right) \delta l_{i} d v+\int\left(\left.T_{i k}\right|_{2}-\left.T_{i k}\right|_{1}\right) n_{k} \delta l_{i} d \Gamma \\
=-\int T_{i k} \partial_{k}\left(\delta l_{i}\right) d v .
\end{gathered}
$$

The displacement is interpolated via the nodal shape function:

$$
\delta l_{i}=\sum_{n} N_{n} \delta_{n i}
$$

- $N_{n}$ is the nodal shape function of the $n^{\text {th }}$ node. Using (5) and (6) the virtual work can be also expressed as:

$$
\begin{gathered}
\delta W=-\int T_{i k} \partial_{k}\left(\sum_{n} N_{n} \delta l_{n i}\right) d v \\
=-\sum_{n}\left(\int T_{i k} \partial_{k} N_{n} d v\right) \delta l_{n i}
\end{gathered}
$$

So the force acting on the $n^{\text {th }}$ node is given as:

$$
f_{n i}=-\int_{\Omega} T_{i k} \partial_{k} N_{n} d v
$$

Using summation for all the nodes in the part, the total force can be written as:

$$
\begin{gathered}
{\left[f_{n}\right]=\left[\begin{array}{l}
f_{n x} \\
f_{n y} \\
f_{n z}
\end{array}\right]=} \\
-\int_{\Omega}\left[\begin{array}{lll}
T_{x x} & T_{x y} & T_{x z} \\
T_{y x} & T_{y y} & T_{y z} \\
T_{z x} & T_{z y} & T_{z z}
\end{array}\right]\left[\begin{array}{c}
\frac{\partial}{\partial x} \\
\frac{\partial}{\partial y} \\
\frac{\partial}{\partial z}
\end{array}\right] N_{n} d v
\end{gathered}
$$




\section{DESCRIPTION OF THE PMLG AND THE SIMULATIONS}

In this paper, it is assumed that the generator's translator is assembled from the permanent magnets and the separators. Likewise, the stator is assembled from two aligned magnetic cores on both sides of the translator with copper coils placed in slots (Figure 1).

It is assumed that the PMLG's stator is assembled from the permanent magnets, the separators, and the upper magnetic core. The separators are made from non-magnetic and nonelectrical conducting material and they are required in order to maintain the position of the permanent magnets against axial displacement. In addition, the PMLG's translator is assembled from the lower magnetic core and the windings.

The magnetic cores of the machine are formed by laminated silicon steel with a 95\% stacking factor and they are treated as magnetically nonlinear material with single value magnetisation characteristics.

The translator teeth are finished with shoes to optimise the flux distribution. Generally, the implementation of shoes decreases both the power ripple and the magnetic reluctance of the air gap. In addition, reduction of the cogging forces in linear machines can be also achieved [16]. The windings' excitation flux is provided by Neodymium-Iron-Boron magnets with magnetisation direction parallel to the Y-axis. Furthermore, in order to increase the accuracy of the simulation results, the PMLG has full translator models and therefore, the influence of the longitudinal ends can be taken into account. Moreover, a repetitive boundary condition is applied to the translator, which is a common approach for linear generator simulations [17].

The main dimensions of the generator are shown in Table 1 . The generator has three-phase windings, where each winding consists of six winding sections connected in series. Furthermore, each winding section consists of six coils connected in parallel. Each winding is shifted by \pm 120 degrees from the other two. Additionally, every winding has a total resistance of $0.9 \mathrm{ohm}$ (base model). The single- and the double-sided generator designs are inspired by [29], although the parameters have been scaled down (where appropriate) to the sizes shown in Table 1. 
Additionally, the motion applied on the translator is an experimentally recorded vertical speed/time sequence of stochastic sea conditions. The sequence was recorded by a wave probe over a period of 20 seconds near the coast of the UK. The main focus of this paper is an optimization of PMLG. So, it is assumed that the translator strictly follows the motion of the water surface.

The number of slots per pole and phase $\mathrm{q}$ for the generator is $1.2(6 / 5)$. This means that five poles have the same length as six three-phase translator slots (or eighteen single-phase slots). For convenience, the value of $q=6 / 5$ can be also presented as 1.2 . Thus, one pole covers 1.2 translator slots. By using such a presentation for $\mathrm{q}$, it is possible to analyse values that differ from the standard ones shown in [16].

\section{ANALITICAL MODEL OF THE PMLG}

The magnetic circuit of the double-side PMLG is shown in Figure 2, in which $\Phi_{P M}$ is the Magneto Motive Force (MMF) source of the permanent magnets and $S_{C}$ and $S_{C 1 m}$ are the reluctances in the magnetic core. Similarly, $S_{1}$ to $S_{19}$ are the magnetic reluctances of the teeth of the translator, $S_{a 1}$ to $S_{a 19}$ are the magnetic reluctances in the air gap between the permanent magnet and every single tooth. They are identified by colour codes on the right-hand side of the figure. In this magnetic circuit, it is assumed that every magnetic pole (covered by the length of the translator teeth) is connected with the closest four translator teeth. At certain positions of the translator where the teeth (end shoes) are located between two magnetic poles, they are linked with both poles and linkage is given as two reluctances: $S_{a i}$ and $S_{a i *}$ ( $i$-tooth number). Furthermore, the values of $S_{P M}$ are the magnetic reluctances of the permanent magnets and $S_{\text {air }}$ represents the reluctance of the air between the magnets outside the translator. These reluctances $\left(S_{\text {air }}\right)$ are constant and they do not affect the main magnetic circuit. The purpose of showing them is to present the magnetic circuit outside the length of the translator.

The magnetic poles located outside of the translator are connected with the final one or two translator teeth. If the permanent magnet (at the longitudinal end) is outside of the translator length, it is considered that the magnet is connected to the final tooth $\left(S_{a 1}\right)$. Alternatively, if the magnet covers the last tooth it is considered that the magnet is connected to the final two translator teeth $\left(S_{18 *}\right.$ and $\left.S_{19}\right)$. 
The analytical modelling technique does not take into account the effects of the saturation of iron in the magnetic cores of the generator.

The voltages generated in the coils are dependent on the magnetic flux passing the teeth surrounding them (flux over $S_{T}$ ). The flux path in the translator, contributing to voltage generation (therefore, to energy harvesting) is through reluctances $S_{C}-S_{T}-S_{a(1-19)}-\Phi_{P M}-$ $S_{P M}-S_{C 1}-S_{P M}-\Phi_{P M}-S_{a(1-19)}-S_{T}-S_{C}$.

However, when a tooth is located between two poles such as the $4^{\text {th }}, 11^{\text {th }}$ and $18^{\text {th }}$ teeth in Figure 2, part of the flux goes through the tooth shoe, bypassing the tooth. For instance, in the case of the $4^{\text {th }}$ tooth, part of the magnetic flux will follow the contour of $S_{a 4}-S_{a 4 *}-\Phi_{P M}-$ $S_{P M}-S_{C 1}-S_{P M}-\Phi_{P M}-S_{a 4}$. Such leakage of flux is not beneficial to energy harvesting and can be considered a loss. A reduction of the flux can be achieved by altering the width of the shoes along the $\mathrm{X}$-axis.

The total magnetic reluctance of a single-sided PMLG's section with a length of 8 teeth can be presented as:

$$
S_{\text {Total }}=4 * S_{E}+2 * S_{P M}+2 * S_{C}
$$

where $S_{\text {Total }}$ is the total magnetic reluctance of the area indicated by shading in Figure 2. Furthermore, where $S_{E}$ is one-half of the reluctance of the translator, it can be calculated as follows:

$$
\begin{gathered}
S_{E}=\frac{S_{T t}{ }^{4}+S_{C}{ }^{3} * S_{T}+6 * S_{T t}{ }^{3} * S_{C}+5 *{S_{C}}^{2} * S_{T t}{ }^{2}}{4 * S_{T t}{ }^{3}+S_{C}{ }^{3}+10 *{S_{T t}}^{2} * S_{C}+6 * S_{C}{ }^{2} * S_{T t}} \\
S_{T t}=S_{T}+S_{a n n}
\end{gathered}
$$

where $n n$ is the number of the reluctances shown on the right-hand side (with code) in Figure 2 and can be presented as:

$$
\begin{gathered}
S_{a n n}=\frac{l_{g a p}}{\mu_{0} * A_{r}} \\
S_{T}=\frac{l_{\text {tooth }}}{\mu_{c} * A_{r}}
\end{gathered}
$$




$$
S_{c}=\frac{l_{\text {core }}}{\mu_{c} * A_{r}}
$$

where $l_{\text {gap }}$ is the length of the air gap between the centre of the permanent magnet and the centre of the shoes and $l_{\text {tooth }}$ is the length of the coil`s slots in the magnetic core. The permeability's of the air and the magnetic core are given by $\mu_{0}$ and $\mu_{c}[\mathrm{H} / \mathrm{m}]$ respectively and $A_{r}$ is the area of the pole face.

Using the equivalent reluctance the magnetic circuit can be presented as simple circuit with an MMF source connected to a single magnetic reluctance. Hopkinson's law is a counterpart to Ohm's law and can be used in magnetic circuits:

$$
\begin{gathered}
\Phi_{P M}=\psi_{m} * S_{E} \\
\psi_{m}=\frac{\Phi_{P M}}{S_{E}}
\end{gathered}
$$

where $\psi_{m}$ is the total magnetic flux of the magnetic circuit (i.e., the flux passing $S_{C 1 m}$ ). Similarly, the magnetic flux density in the air gap can be presented as:

$$
B=\frac{\psi_{m}}{A_{r}}
$$

The analytical calculations are performed using Matlab and the results for the flux density in the air gap show a difference of $5.5 \%$ in comparison with the FEA results for a static simulation.

\section{SIMULATED FEA RESULTS}

\subsection{The Effect of Number of Slots per Pole and Phase $q$ on the PMLG Performance}

The forces affect the bearings and the supporting structure in different ways and therefore, minimising them is important with regard to maintenance costs and the structural integrity of the WEC. 
The number of slots per pole and phase represents the distribution of the magnets with respect to the stator slots. It can be calculated by:

$$
q=\frac{P_{p}}{3 S_{p}}
$$

- 3 is the number of phases,

- $S_{p}$ is the single phase stator slots pitch,

- $P_{p}$ is the pole pitch.

In the paper, the value of $q$ is changed by varying of the pole pitch at constant stator slot pitch.

In this paper, the magnetic force levels for different values of $q$ are presented as single numbers, where the number is evaluated from the simulated force in the time domain. The intention is to present an optimal number for $q$. The method for calculating the single numbers by using the time domain graphs for the cogging forces is explained below:

1. The cogging force data in time domain is converted to absolute values.

2. The value of the peak force and $60 \%$ of the peak are established.

3. The upper part of the graph (from $60 \%$ to $100 \%$ ) is analysed.

4. The values from $60 \%$ to $100 \%$ where the tangent to the graph is parallel to the time axis are obtained (i.e. the force peaks).

5. Finally, an average of the values obtained and this average number is taken as representative of the force level in the sample graph.

The main objective of the above technique is to calculate two factors. The first is to show the average amplitude of the peak forces (60\% to $100 \%)$ and the other is to take into account how often the generator reach forces higher than $60 \%$.. For example, if the majority of the peaks lie between $60 \%$ and $70 \%$, a lower average will be established in comparison with the case where the majority of forces lie between $70 \%$ and $80 \%$. Therefore, by using this method, not only can the peak force can be taken into account but also, it can be assessed how often that peak force is reached.

The purpose of this approach is to evaluate a single number, which is representative of the peak forces of the entire simulation period in the time domain. The minimum level (in this case 
$60 \%$ ) can be altered. The decision that only forces higher than $60 \%$ are to be included is made in order to include a greater number of peaks. The high number of peaks is important in reducing the error in the peak forces from the FEA simulations.

In this section, the magnetic forces between the stator and translator are shown in the $\mathrm{X}$ - and $\mathrm{Y}$-axes. The forces parallel to the $\mathrm{X}$-axis do not affect the bearings directly due to the free bearing motion on the X-axis but they do cause latching of the translator, unwanted noise and vibrations [3]. The forces parallel to the Y-axis are directly destructive to the bearings and the supporting structure due to the translator's locked freedom on the Y-axis.

The forces affect the bearings and the supporting structure in different ways and therefore, minimising them is important with regard to maintenance costs and the structural integrity of the WEC.

To perform the simulations in the Y-axis, 3D models with high mesh resolution are used to increase the accuracy for the force calculation. The results reveal that the highest forces and the highest RMS power output occur when $\mathrm{q}=1$.

In Figure 4, a presentation of all the forces as single number is shown. Moreover, in the same figure, the RMS powers for each q are calculated over the complete time series of the translator displacement. The current density for the models with a $50 \mathrm{~kW}$ output power $(\mathrm{q}=1)$ is 0.8 $\mathrm{A} / \mathrm{mm} 2$. It can be seen that the cogging forces follow a very similar pattern to those of the single-sided PMLG. However, their magnitude is approximately twice as great. The reason for this is the double sided structure of the generator doubles the number of teeth attracting the PMs. Moreover, the harvested electrical energy is also higher.

In Table 2, the Force-to-Power ratio for the $\mathrm{X}$ - and $\mathrm{Y}$-axes is presented for all values of $\mathrm{q}$. As the aim of the optimisation is to minimise forces and maximise electrical power, the lowest numbers in Table 2 define the optimal value for $\mathrm{q}$.

The results for the $\mathrm{X}$-axis reveal $\mathrm{q}=1.1$ as optimal and the results for the $\mathrm{Y}$-axis reveal that $\mathrm{q}=$ 0.9 is optimal. This ratio is important because the maximum output power can be determined by knowing the level of the acceptable forces for the bearings (Y-axis) and the level of the acceptable vibrations (X-axis). Therefore, for different bearing systems and different WEC supporting structures the numbers could vary. For the purpose of this optimisation, the optimal number of $\mathrm{q}$ is suggested based on the lowest Force-to-Power ratio. 


\subsection{The Effect of Different Numbers of Winding Sections on the PMLG Performance}

In this section, translators with different number of winding sections are simulated. Results obtained from models with windings distributed from two to nine sections are shown. As the generators simulated in this section have a different number of winding sections, the total winding resistance differs and it can be calculated by:

$$
\mathrm{R}_{\text {winding }}=2 * 0.15 * \mathrm{p}
$$

where: $\mathrm{p}$ is the number of winding sections connected in series.

To perform the simulations in the $\mathrm{Y}$-axis, 3D models with high mesh resolution are used to increase accuracy for the force calculation. The simulation results show that the highest force appears for those generators with the lower number of winding sections. The effect from the misalignment between the stator poles and translator teeth $(\mathrm{q}=1.2)$ is the main reason for this result. In short translators this misalignment has less effect; however, for longer translators the misalignment becomes higher than the length of the pole. Therefore, the peaks of the cogging forces for every tooth do not occur at the same point in time. Additionally, the result for the RMS power output is also shown in Figure 5. It can be seen that the highest power output can be achieved with five winding sections.

To compare the generator models on the same basis regarding the PM volume, the simulated models should have the same length of maximum translation of the translator. Therefore, the total length of the stator is assumed to be the length of the translator plus an additional 1.5 metres, where free maximum translation is allowed. In Figure 6, the volume of permanent magnet material is calculated for generators with different numbers of sections. The results are averaged to the nearest magnetic pole.

Table 3 shows the Force-to-Power ratio in the $\mathrm{X}$ - and $\mathrm{Y}$-axes for generators with different number of winding sections and Power-to-PM volume ratio. The results reveal an optimal number of three winding sections for the $\mathrm{X}$-axis force and seven sections for the $\mathrm{Y}$-axis force.

Another coefficient representing the efficiency of the generator is the Power-to-PM volume ratio (Table 3). This coefficient is not discussed in the previous section because of the small 
difference in the volumes of the PM material for different q. The aim here is to maximise the ratio; therefore, the generator with four sections can be considered optimal for this criterion.

The importance of such a comparison is triggered by the price of the permanent magnets. Recent price changes of permanent magnets by almost 800\% (for the period 04/2010 to 07/2011) [30] makes the permanent magnet material the most expensive component of the PMLGs.

\subsection{OPTIMIZATION OF THE PMLG}

From the results shown in Figure 3, it can be observed that the highest electrical power is harvested at $\mathrm{q}=1$. At this value of the slots per pole and phase, a perfect alignment among the coils and permanent magnets is established. Consequently, the generated coil voltages will be in phase and therefore, the highest total generated voltage can be achieved. However, the iron pole shoes become aligned with the permanent magnets and hence, strong cogging force is generated. On the other hand, the results shown in Figure 5, suggest that generally high numbers of winding sections reduces the cogging force due to the misalignment among the peaks of the magnetic forces between the PMs and the steel shoes. Based on the above results, it is observed that a long stator, which consists of a number of short stators, can deliver high output power, where the power is combined from the individual short stators. Furthermore, low cogging force can be achieved by increasing the total length of the stator, where the length is the combined lengths of the small stators.

In this section, an optimised generator is suggested taking into account the results presented in Section 3.3.2. The aims of the optimisation in decreasing order of their importance are:

1. Low force parallel to the $\mathrm{X}$-axis

2. Low force parallel to the Y-axis

3. High electrical output power

4. Low volumes of permanent magnet material used in the generator assembly.

Higher importance is given to those aims related to maintenance costs, which could be considerably high, due to the offshore and/or underwater operating conditions. 
With regard to the above order of aims, it can be considered that the optimal solution is when $\mathrm{q}$ $=1.1$ rather than $\mathrm{q}=0.9$. The reason for this decision is the small difference between the Forceto-Power ratio in the $\mathrm{Y}$-axis (between $\mathrm{q}=0.9$ and $\mathrm{q}=1.1$ ) and the big difference in the Forceto-Power ratio in the $\mathrm{X}$-axis (between $\mathrm{q}=0.9$ and $\mathrm{q}=1.1$ ).

To increase the power output and to reduce the cogging forces, a magnetically split translator is suggested. In this way the generator will be assembled from two separated translator cores translating together. The main idea is to take two short magnetic cores with low $\mathrm{X}$-axis force and combine them in a long one delivering low Y-axis force. The new translator is assembled from two yokes containing three winding sections. The choice for the number of winding sections is based on delivering low force in the X-direction. Furthermore, the total length of the translator of the optimised model has a very similar length to a generator with six winding sections in the $\mathrm{Y}$-axis. The simulated results for the $\mathrm{X}$ - and $\mathrm{Y}$-axes forces for the optimised generator are shown in Figure 8c.

The simulation results reveal that the RMS output power is $42.4 \mathrm{~kW}$ and that the single force numbers for the $\mathrm{X}$ - and $\mathrm{Y}$-axes are $2.92 \mathrm{kN}$ and $0.8 \mathrm{kN}$ respectively. Furthermore, the Powerto-Magnet volume ratio is $2377 \mathrm{~W} / \mathrm{m} 3$ and the volume of the permanent magnet material in the PMLG is $0.018 \mathrm{~m} 3$.

High output power with regard to the amount of permanent magnet material used in the generator is achieved. The optimised model contains a very similar amount of permanent magnet material compared with the generator with six winding sections. However, the Powerto-PM volume ratio for a generator with six winding sections is 1019 and for the optimised model it is 2377 [W/m3], resulting in a $233 \%$ increase of the Power-to-PM volume.

Another advantage of the optimised model is the reduction of the $\mathrm{X}$-axis forces by $55 \%$ and of the $\mathrm{Y}$-axis forces by $28 \%$, compared with the PMLG with six winding sections. Moreover, the magnetically separated sub-yokes of the translator are smaller physically and therefore, it is easier to maintain, transport and handle them.

\section{CONCLUSIONS}

The research in this paper began with an investigation of the factors affecting the cogging 
force and power output in a single- and double-sided PMLGs, where the influence of the different design solutions has been presented. Furthermore, a method for calculating a single number, representing the cogging force level of a generator has been suggested.

Additionally, a double-sided PMLG is investigated with regard to the same parameters. The main analyses in this paper are focused on suggesting an optimised design for a double-sided PMLG. As a result, a design with a magnetically separated yoke delivering better performance is proposed. The simulated results disclose that the optimised model delivers a reduction in the $\mathrm{X}$ - and the $\mathrm{Y}$-axes forces by $55 \%$ and $28 \%$, respectively and an increase of the output power by $233 \%$ in comparison with a model with a non-separated translator with the same volume of PM material.

\section{ACKNOWLEDGEMENTS}

The authors would like to thank the PRIMaRE project for the sponsorship and the support for this work.

\section{References}

[1] K. Rhinefrank, E. B. Agamloh, A. von Jouanne, A. K. Wallace, J. Prudell, K. Kimble, J. Aills, E. Schmidt, P. Chan, B. Sweeny and A. Schacher, "Novel ocean energy permanent magnet linear generator buoy," Renewable Energy, vol. 31, pp. 1279-1298, 7, 2006.

[2] J. K. H. Shek, D. E. Macpherson, M. A. Mueller and J. Xiang, "Reaction force control of a linear electrical generator for direct drive wave energy conversion," Renewable Power Generation, IET, vol. 1, pp. 17-24, 2007.

[3] J. Prudell, M. Stoddard, E. Amon, T. K. A. Brekken and A. von Jouanne, "A PermanentMagnet Tubular Linear Generator for Ocean Wave Energy Conversion," Industry Applications, IEEE Transactions On, vol. 46, pp. 2392-2400, 2010.

[4] N. Hodgins, O. Keysan, A. S. McDonald and M. A. Mueller, "Design and Testing of a Linear Generator for Wave-Energy Applications," Industrial Electronics, IEEE Transactions On, vol. 59, pp. 2094-2103, 2012.

[5] D. Li, B. Bai, Q. Yu and D. Chen, "Cogging force minimization in a permanent magnet linear generator for sea wave energy extraction applications," in Energy and Environment Technology, 2009. ICEET '09. International Conference On, 2009, pp. 552-554.

[6] M. Ashabani, J. Milimonfared, J. Shokrollahi-Moghani, S. Taghipour and M. Aghashabani, "Mitigation of Cogging Force in Axially Magnetized Tubular Permanent-Magnet Machines Using Iron Pole-Piece Slotting," Magnetics, IEEE Transactions On, vol. 44, pp. 2158-2162, 2008. 
[7] J. K. H. Shek, D. E. Macpherson and M. A. Mueller, "Experimental verification of linear generator control for direct drive wave energy conversion," Renewable Power Generation, IET, vol. 4, pp. 395-403, 2010.

[8] C. Boström and M. Leijon, "Operation analysis of a wave energy converter under different load conditions," Renewable Power Generation, IET, vol. 5, pp. 245-250, 2011.

[9] Yi Pu, Shijie Zhou, J. Gu, Hao Chen and Chenjin Zhang, "A novel linear switch reluctance generator system," in Automation and Logistics (ICAL), 2012 IEEE International Conference On, 2012, pp. 421-427.

[10] Zanxiang Nie, Xi Xiao, R. McMahon, P. Clifton, Yunxiang Wu and Shiyi Shao, "Emulation and Control Methods for Direct Drive Linear Wave Energy Converters," Industrial Informatics, IEEE Transactions On, vol. 9, pp. 790-798, 2013.

[11] N. P. Gargov and A. F. Zobaa, "Multi-phase air-cored tubular permanent magnet linear generator for wave energy converters," Renewable Power Generation, IET, vol. 6, pp. 171176, 2012.

[12] N. Gargov and A. F. Zobaa, "Multiphase tubular permanent magnet linear generator for wave energy converters," in Renewable Power Generation (RPG 2011), IET Conference On, 2011, pp. 1-5.

[13] O. Keysan and M. A. Mueller, "A linear superconducting generator for wave energy converters," in Power Electronics, Machines and Drives (PEMD 2012), 6th IET International Conference On, 2012, pp. 1-6.

[14] N. M. Kimoulakis, A. G. Kladas and J. A. Tegopoulos, "Cogging Force Minimization in a Coupled Permanent Magnet Linear Generator for Sea Wave Energy Extraction Applications," Magnetics, IEEE Transactions On, vol. 45, pp. 1246-1249, 2009.

[15] N. P. Gargov, A. F. Zobaa and G. A. Taylor, "Structural designs and forces in direct drive linear generators for marine wave power generation," in Universities Power Engineering Conference (UPEC), 2012 47th International, 2012, pp. 1-6.

[16] I. A. Ivanova, O. Agren, H. Bernhoff and M. Leijon, "Simulation of wave-energy converter with octagonal linear generator," Oceanic Engineering, IEEE Journal Of, vol. 30, pp. 619-629, 2005.

[17] O. Danielsson, M. Eriksson and M. Leijon, "Study of a longitudinal flux permanent magnet linear generator for wave energy converters," Int. J. Energy Res., vol. 30, pp. 11301145, 2006.

[18] O. Danielsson and M. Leijon, "Flux Distribution in Linear Permanent-Magnet Synchronous Machines Including Longitudinal End Effects," Magnetics, IEEE Transactions On, vol. 43, pp. 3197-3201, 2007. 
[19] V. D. Colli, P. Cancelliere, F. Marignetti, R. Di Stefano and M. Scarano, "A TubularGenerator Drive For Wave Energy Conversion," Industrial Electronics, IEEE Transactions On, vol. 53, pp. 1152-1159, 2006.

[20] M. Prado and H. Polinder, "Direct drive in wave energy conversion - AWS full scale prototype case study," in Power and Energy Society General Meeting, 2011 IEEE, 2011, pp. 17.

[21] N. M. Kimoulakis, P. E. Kakosimos and A. G. Kladas, "Power generation by using point absorber wave energy converter coupled with linear permanent magnet generator," in Power Generation, Transmission, Distribution and Energy Conversion (MedPower 2010), 7th Mediterranean Conference and Exhibition On, 2010, pp. 1-5.

[22] J. Falnes, "Principles for capture of energy from ocean waves," Department of Physics, NTNU, Trondheim, Norway, Tech. Rep. N-7034, 1997.

[23] K. Thorburn and M. Leijon, "Farm size comparison with analytical model of linear generator wave energy converters," Ocean Eng., vol. 34, pp. 908-916, 4, 2007.

[24] Evans D., "A theory for Wave-Power absorption by oscillating bodies," Journal of Fluid Mechanics, vol. 77, 1976.

[25] H. Polinder, J. G. Slootweg, M. J. Hoeijmakers and J. C. Compter, "Modeling of a linear PM Machine including magnetic saturation and end effects: maximum force-to-current ratio," Industry Applications, IEEE Transactions On, vol. 39, pp. 1681-1688, 2003.

[26] Yang G., D. Chun-yang, Lu Y. and Sun L., "Model of permanent magnet inductor type synchronous motor," in Applied Power Electronics Conference and Exposition, 2003. APEC '03. Eighteenth Annual IEEE, 2003, pp. 69-74 vol.1.

[27] Yan Xiuke, Xie Dexin, Zhang Yihuang and Yu Cunzhan, "Application of nodal force method to switched reluctance motor," in Electrical Machines and Systems, 2003. ICEMS 2003. Sixth International Conference On, 2003, pp. 174-176 vol.1.

[28] Jae Seop Ryu, Yan Xiuke, Chang Seop Koh, Xie Dexin and Song-Yop Hahn, "3D adaptive finite element method with edge elements [for machine calculations]," in Electrical Machines and Systems, 2001. ICEMS 2001. Proceedings of the Fifth International Conference On, 2001, pp. 1174-1177 vol.2.

[29] O. Danielsson, K. Thorburn, M. Eriksson, M. Leijon, "Permanent magnet fixation concepts for linear generator," in Proceedings of the 5th European Wave Energy Conference, Cork (Ireland), 2003, pp. pp.117-124.

[30] H. Humphries, "Rare earth elements: The global supply chain," Congressional Research Service, 2011. 


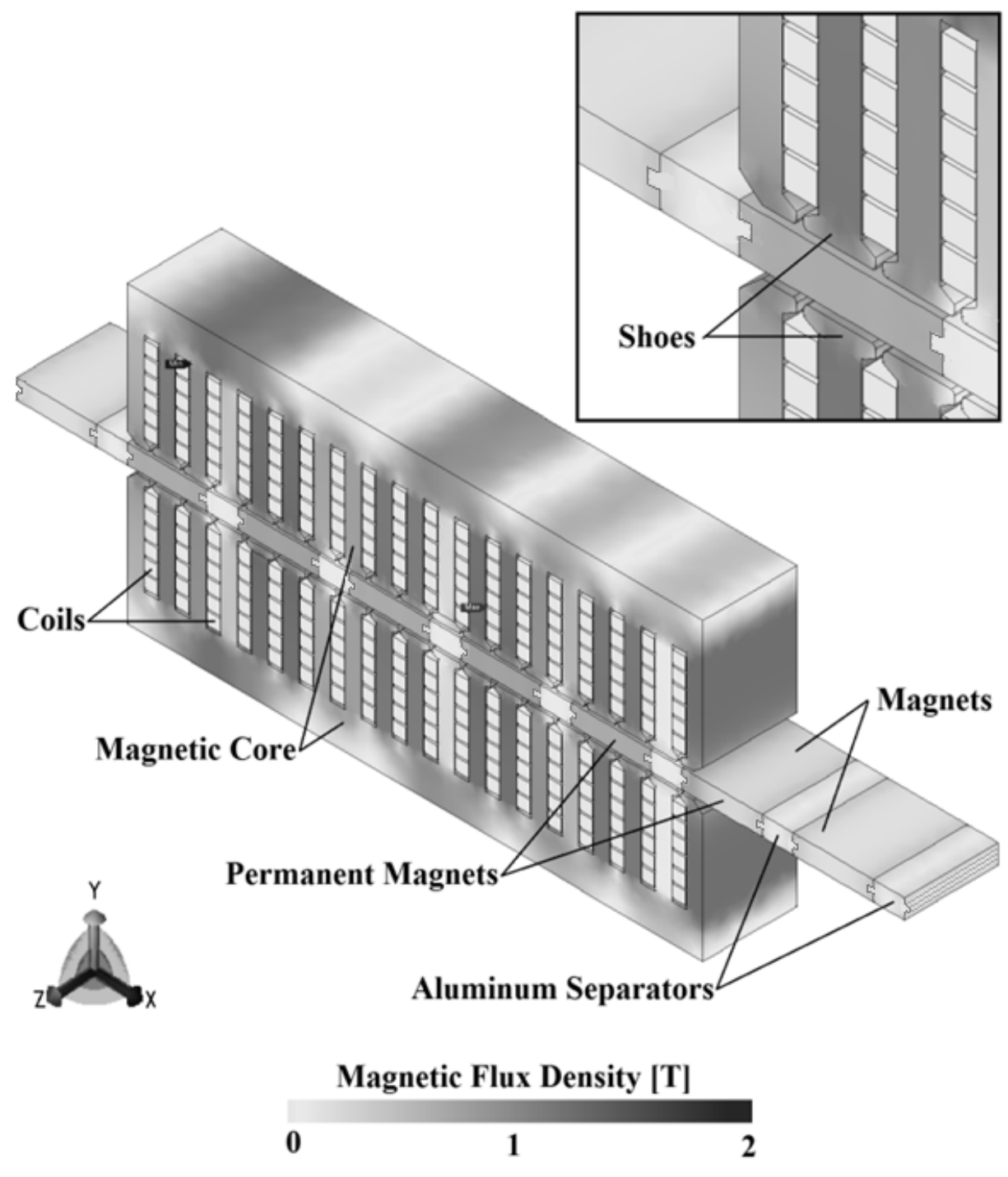

(a) Overview of the base model of the PMLG 

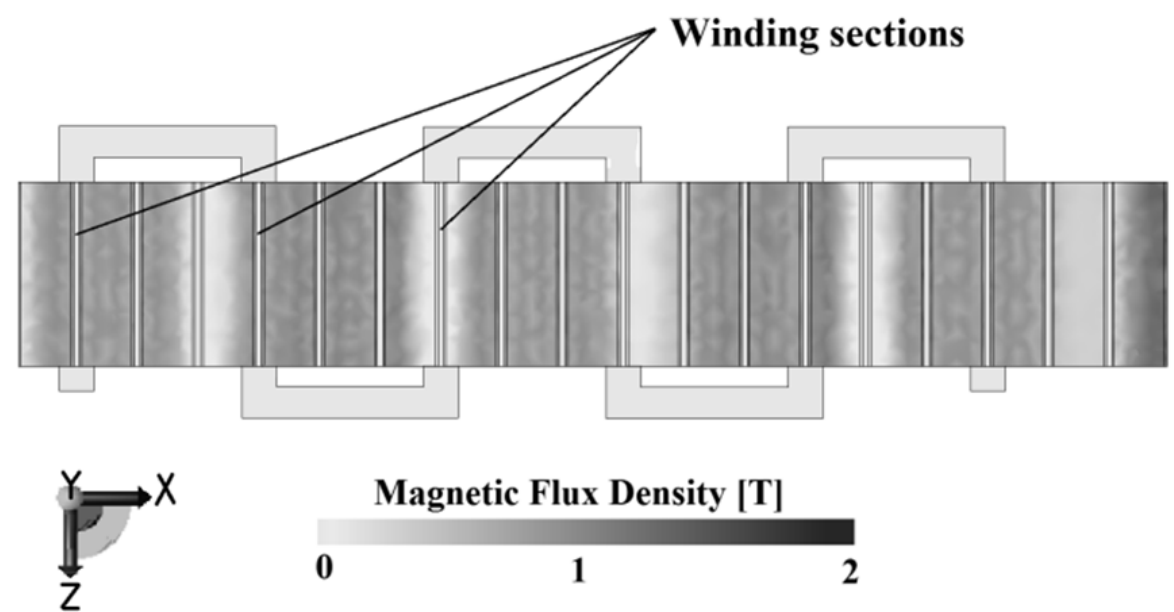

(b) Single phase distribution in the lower magnetic core, the translator and upper magnetic core are not displayed

Figure 1 PMLG with six winding sections 


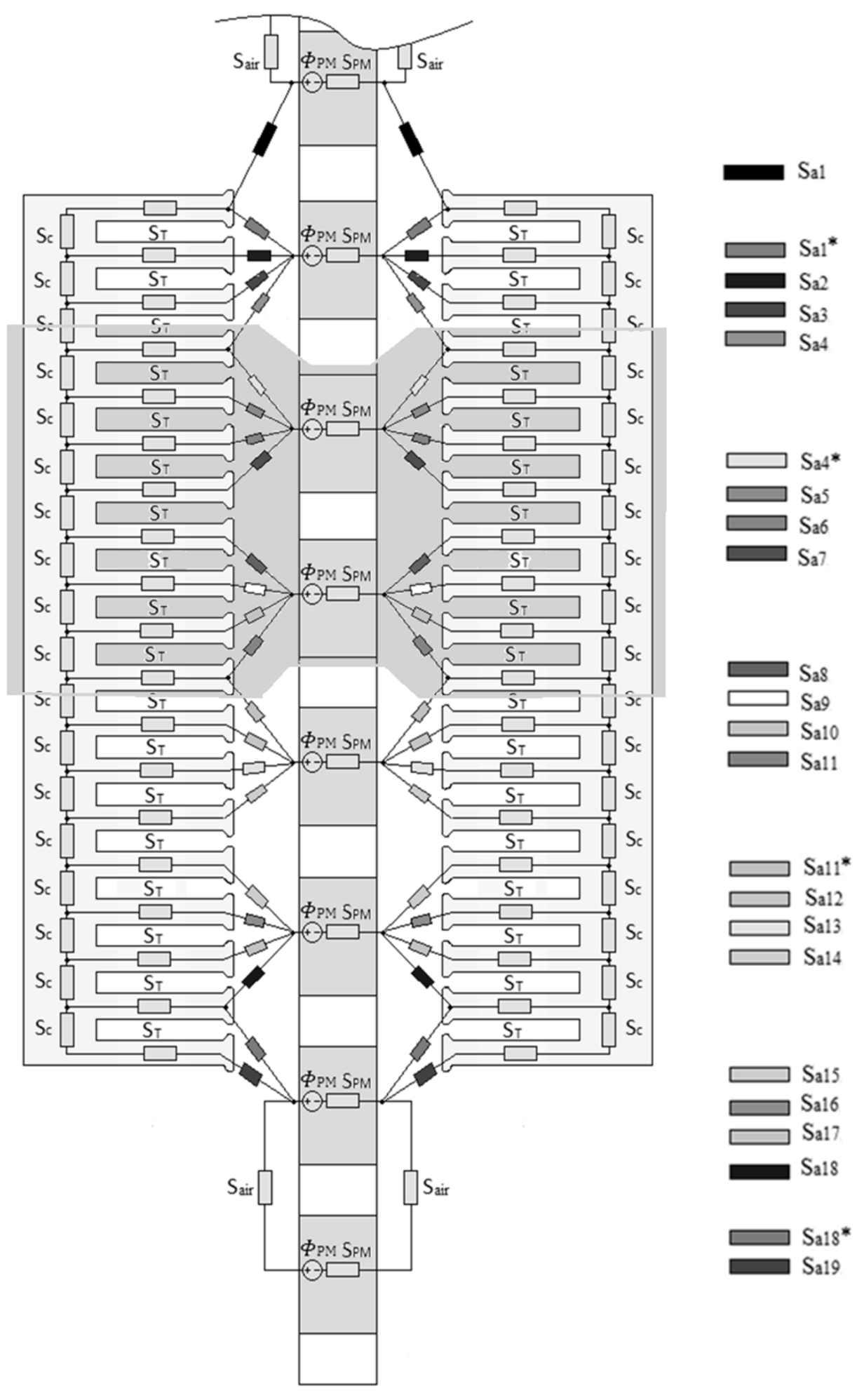

Figure 2 Magnetic circuit of double sided PMLG 


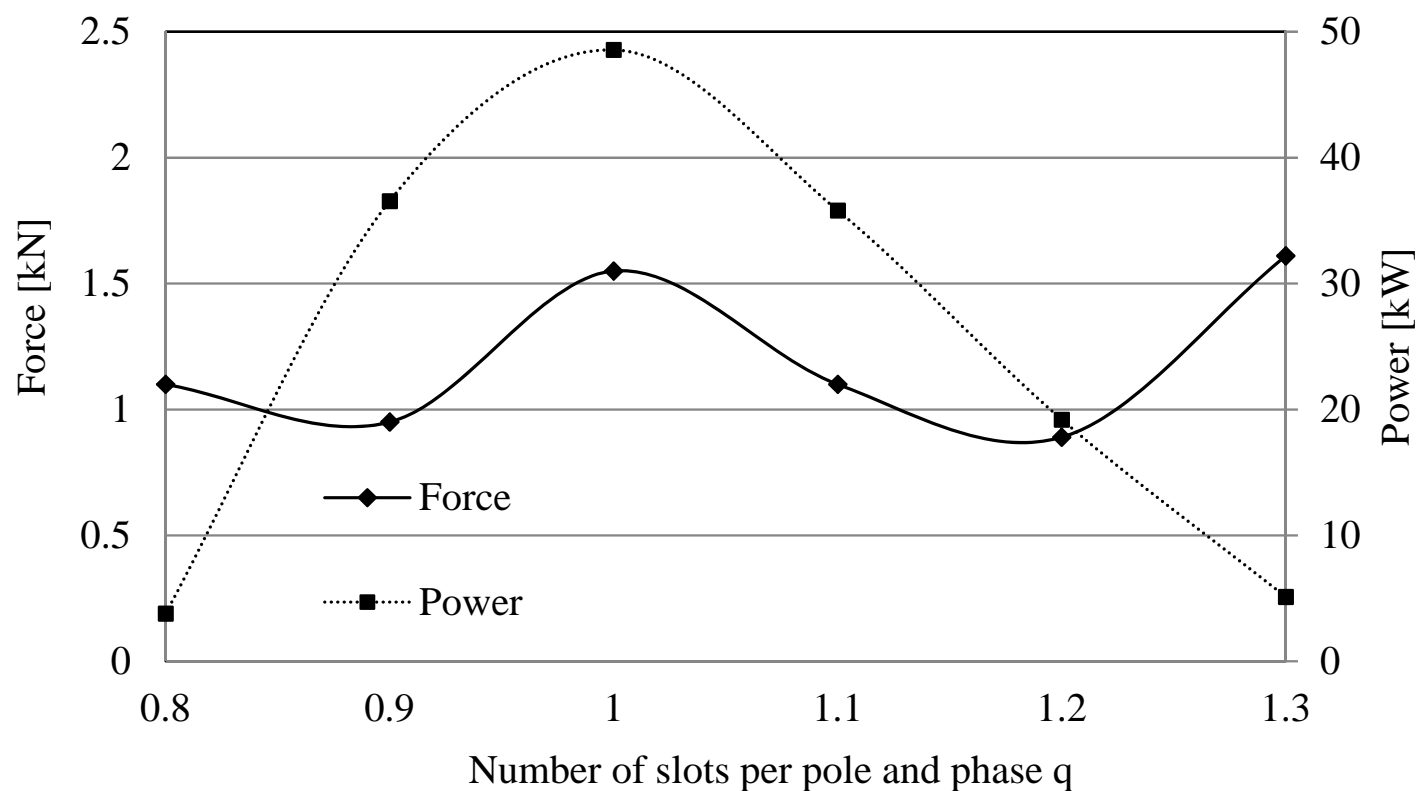

Figure 3 Y-axis forces and RMS power for double-sided PMLG

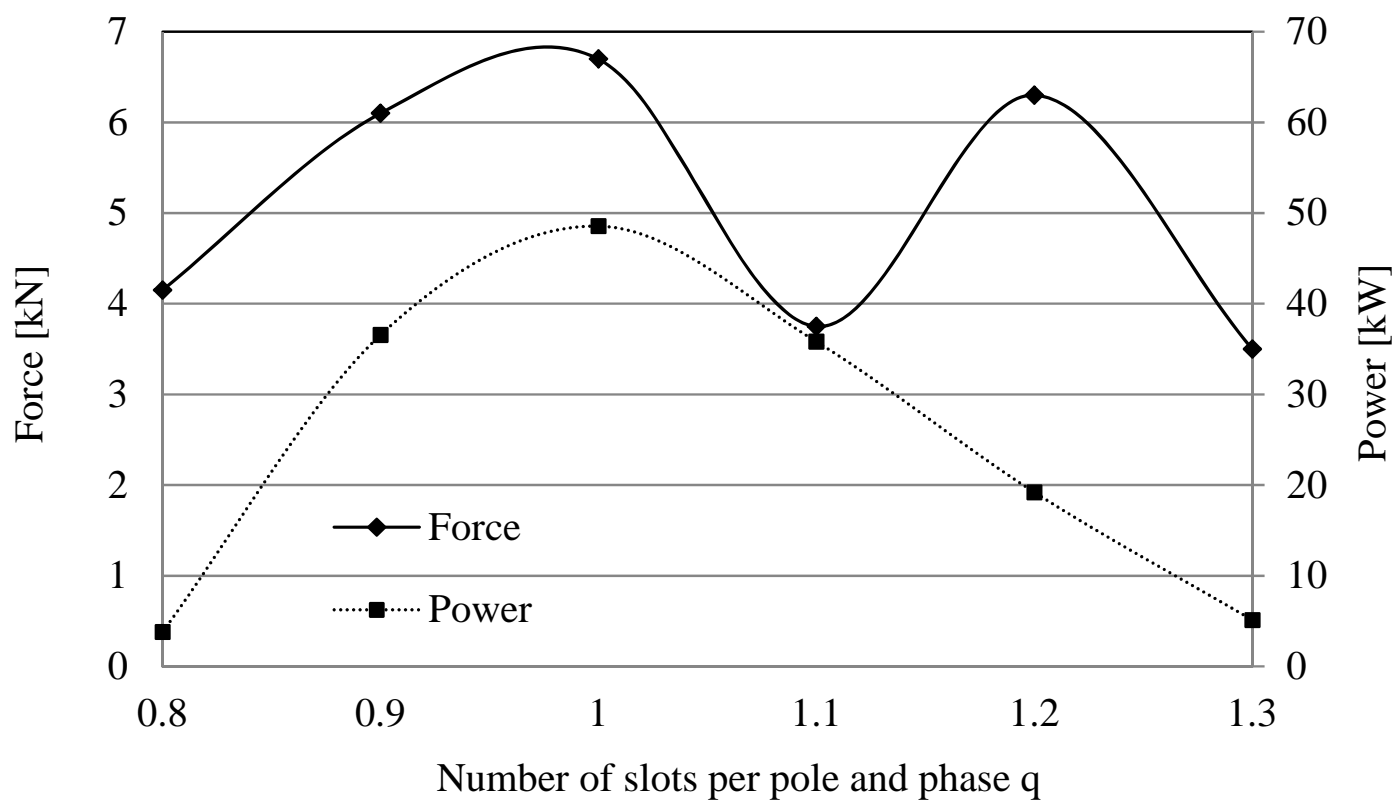

Figure $4 \mathrm{X}$-axis forces and RMS power for double-sided PMLG 


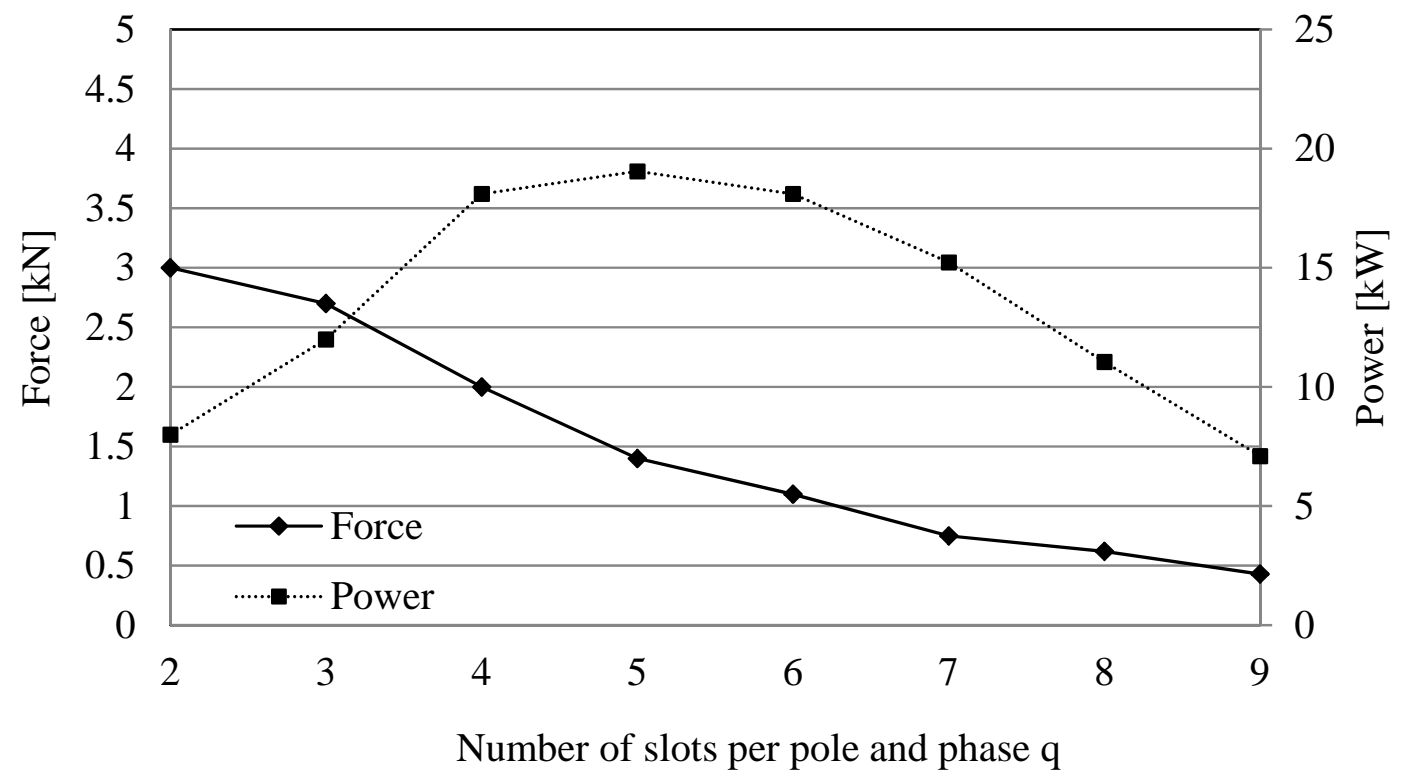

Figure 5 Y-axis forces and RMS power for double-sided PMLG

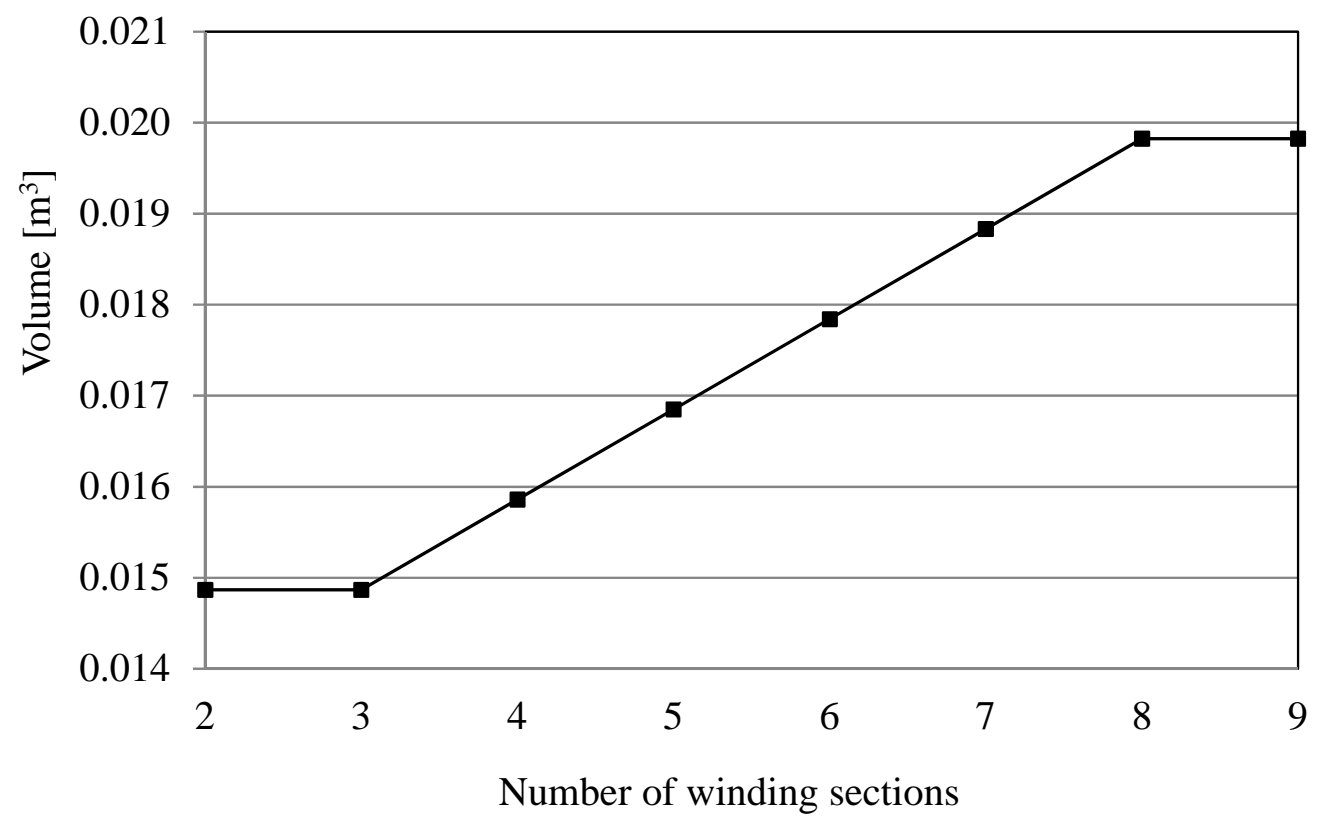

Figure 6 Volume of PM material versus different number of sections 


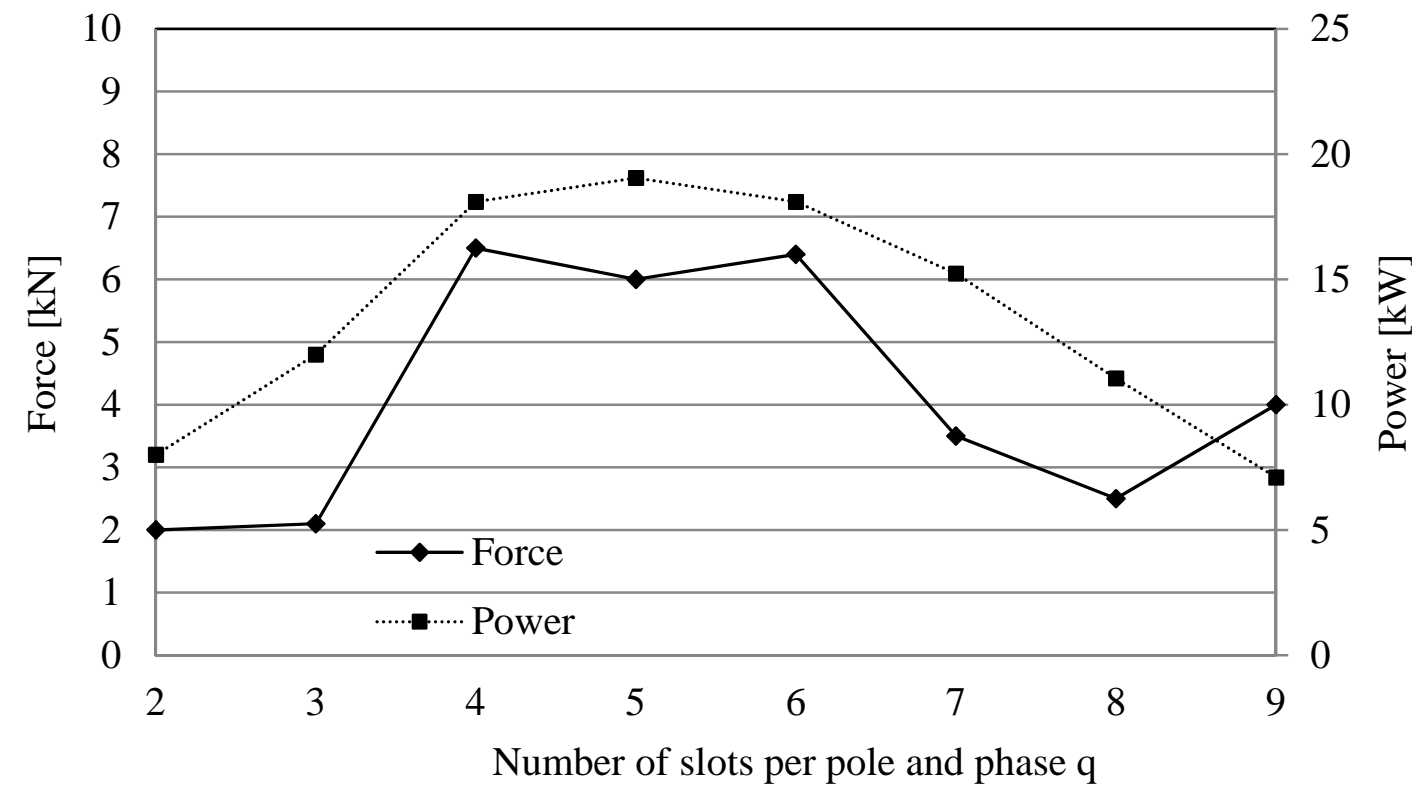

Figure 7 X-axis forces and RMS power for double sided PMLG

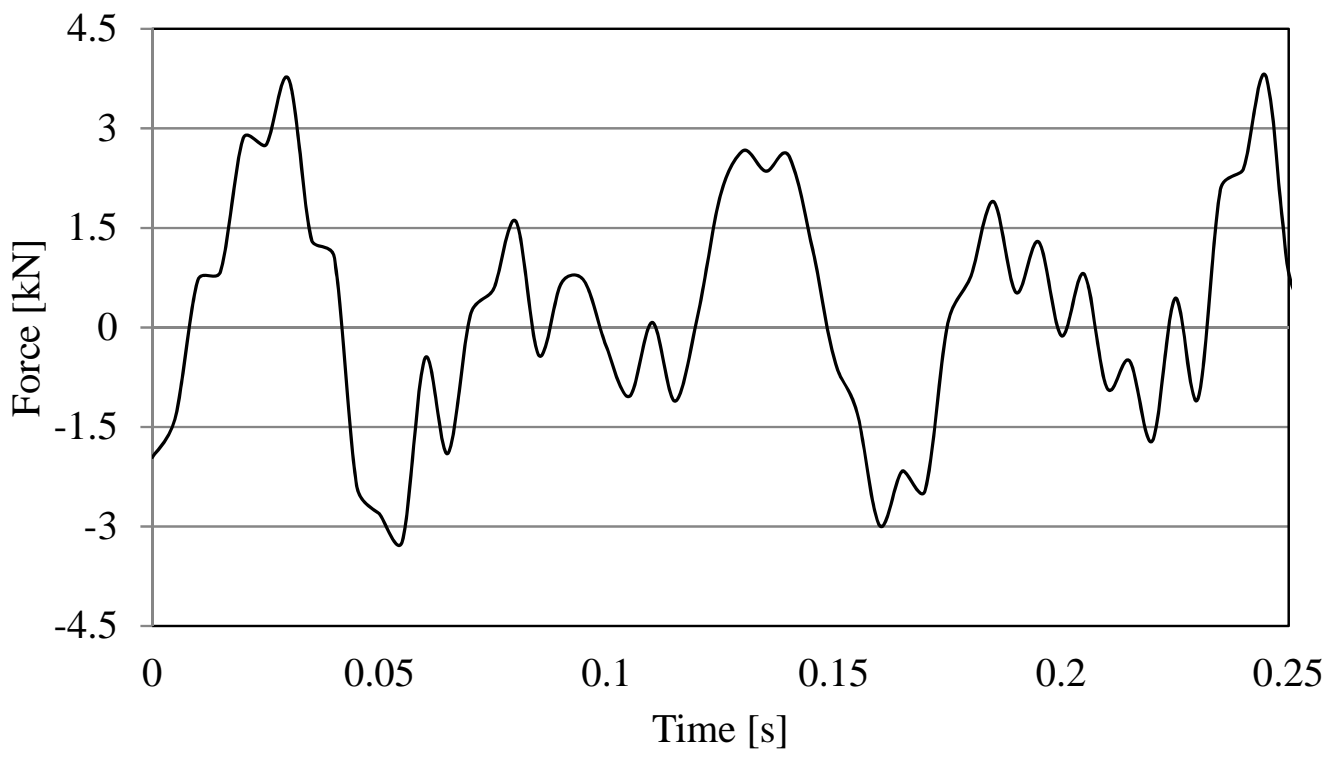

(a) X-axis forces 


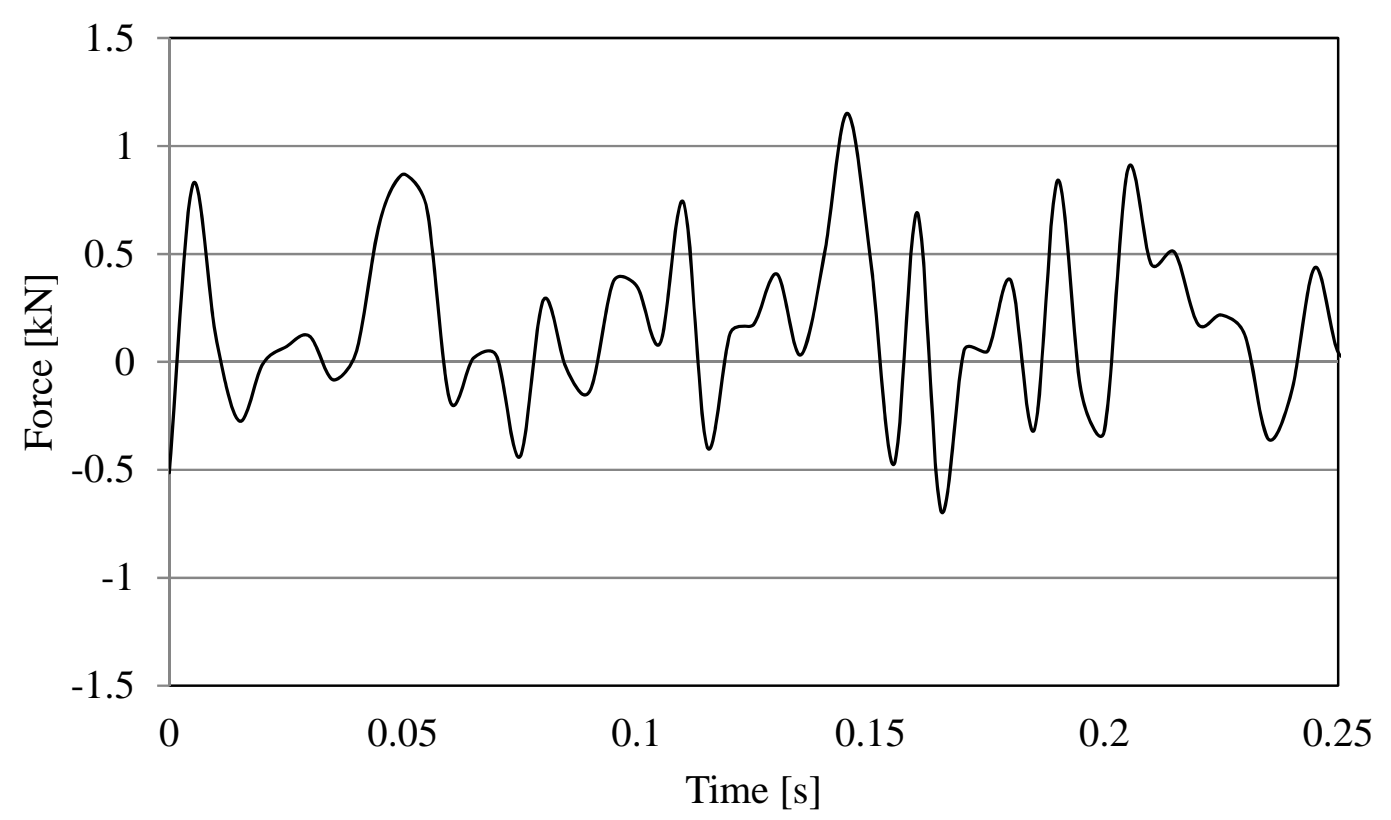

(b) Y-axis forces

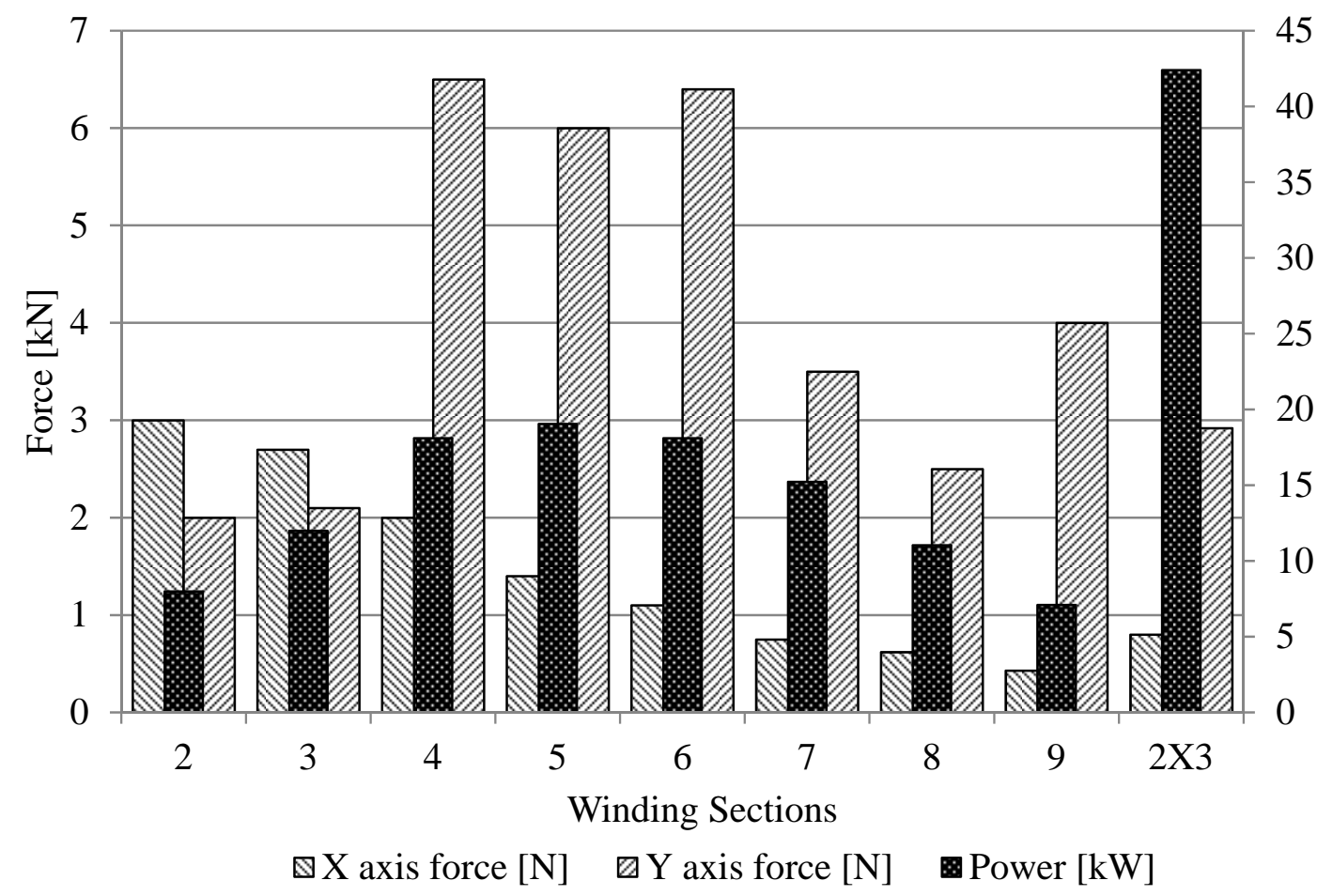

(c) Power and force comparison between PMLGs with different winding sections and the optimized model (2x3)

Figure $8 \mathrm{X}$ - and $\mathrm{Y}$-axes magnetic forces in the optimised model 

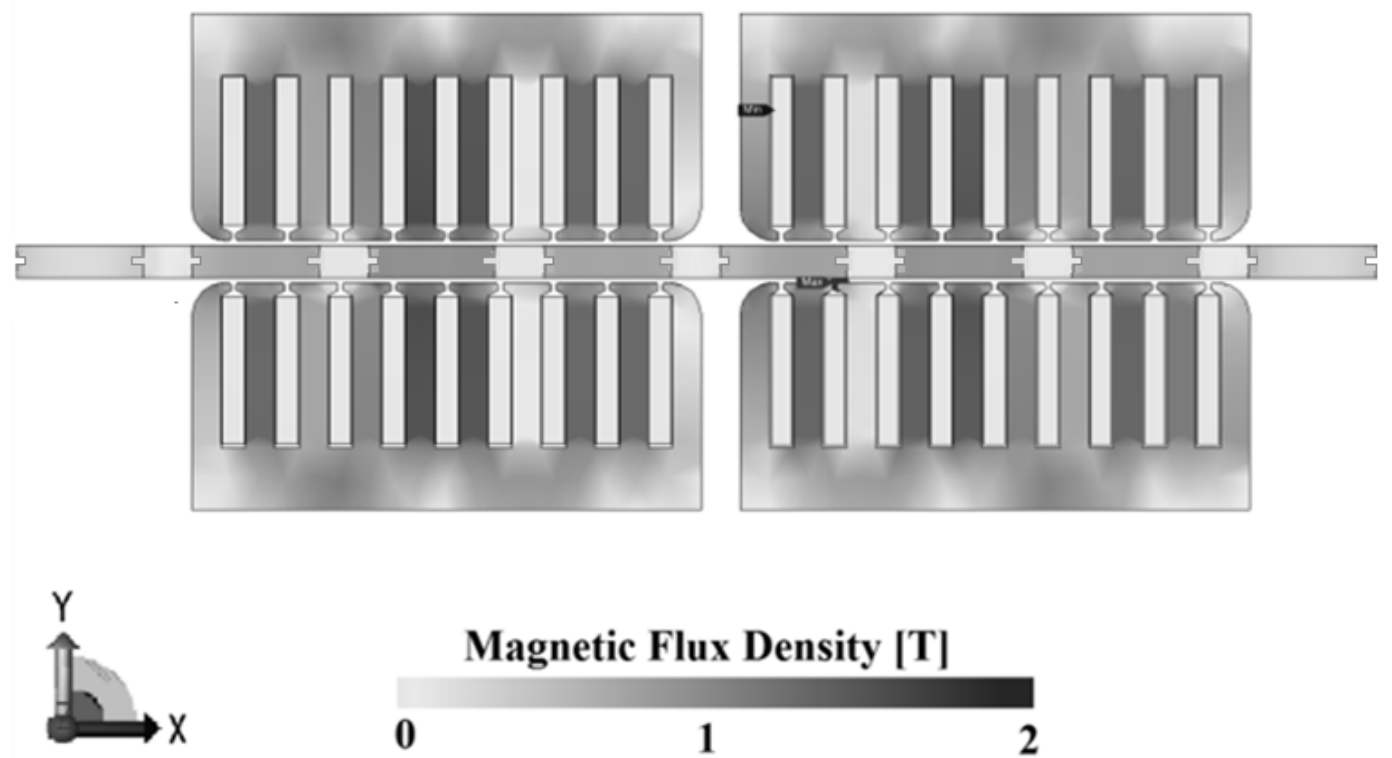

Figure 1Magnetic flux density in the optimised generator model 
Table 1Main Dimensions of the double sided PMLG

\begin{tabular}{|c|c|c|}
\hline \multicolumn{3}{|c|}{ DIMENSIONS } \\
\hline Parameter & \multicolumn{2}{|c|}{ Axis } \\
\hline Translator length [mm] & $\mathrm{X}$ & 612 \\
\hline Translator width [mm] & $\mathrm{Z}$ & 600 \\
\hline Winding length $[\mathrm{mm}]$ & $\mathrm{Y}$ & 88 \\
\hline Translator height [mm] & $\mathrm{Y}$ & 318 \\
\hline Permanent magnet length [mm] & $\mathrm{X}$ & 85 \\
\hline Pole pitch length [mm] & $\mathrm{X}$ & 118.8 \\
\hline Coil slot length [mm] & $\mathrm{X}$ & 15 \\
\hline Translator teeth length [mm] & $\mathrm{Y}$ & 18 \\
\hline Air gap length [mm] & $\mathrm{Y}$ & $2 \times 3$ \\
\hline \multicolumn{3}{|c|}{ ELECTRICAL CHARACTERISTICS } \\
\hline Number of turns per winding section & & 24 \\
\hline Number of turns per coil & & 4 \\
\hline Number of slot per pole and phase, $q$ & & $1.2(6 / 5)$ \\
\hline Total Winding resistance [ohm] & & 1.8 \\
\hline Resistive three-phase star connected load [ohm] & & 5 \\
\hline
\end{tabular}

Table 2Force-to-Power ratio for $\mathrm{X}$ - and $\mathrm{Y}$-axes

\begin{tabular}{|c|c|c|}
\hline$q$ & $\mathrm{X}$-axis [N/W] & Y-axis [N/W] \\
\hline 0.8 & 1.09268 & 0.28963 \\
\hline 0.9 & 0.16689 & 0.02599 \\
\hline 1 & 0.13797 & 0.03192 \\
\hline 1.1 & 0.10472 & 0.03072 \\
\hline 1.2 & 0.32813 & 0.04635 \\
\hline 1.3 & 0.68359 & 0.31445 \\
\hline
\end{tabular}


Table 3Force-to-Power [N/W] and Power-to-PM volume ratio [W/m3] ratios for X- and Yaxes

\begin{tabular}{|c|c|c|c|}
\hline \multicolumn{2}{|c|}{$\begin{array}{c}\text { X-axis } \\
\text { YN/W] }\end{array}$} & $\begin{array}{c}\text { Y-axis } \\
{[\mathrm{N} / \mathrm{W}]}\end{array}$ & $\begin{array}{c}\text { Power-to-PM volume ratio } \\
{\left[\mathrm{W} / \mathrm{m}^{3}\right]}\end{array}$ \\
\hline Number of sections & 0.250 & 0.375 & 579 \\
\hline 2 & $\mathbf{0 . 1 7 5}$ & 0.225 & 862 \\
\hline 3 & 0.359 & 0.110 & $\mathbf{1 1 5 6}$ \\
\hline 4 & 0.299 & 0.070 & 1125 \\
\hline 5 & 0.354 & 0.061 & 1019 \\
\hline 6 & 0.230 & $\mathbf{0 . 0 4 9}$ & 776 \\
\hline 7 & 0.226 & 0.056 & 342 \\
\hline 8 & 0.563 & 0.061 & 329 \\
\hline 9 & & & \\
\hline
\end{tabular}

